\title{
Prevalence of Dermatoses in Rural Paediatric Population
}

\author{
Hadiuzzaman $M^{1}$, Hasibur $M R^{2}$, Nahida I $I^{3}$, Islam $M S^{4}$, Sabrina $A M^{5}$, Bhuyan $M K J^{6}$
}

\begin{abstract}
The spectra of the prevalence of skin diseases vary worldwide and from country to country. Therefore the information about the local prevalence of diseases is very important in helping the development of appropriate health improvement policies for promotion of better management. To document the types of skin disorders prevalent among rural children attending the Community Based Medical College Hospital out patient department, Mymensigh, a defined population based study was undertaken. The medical register from the Hospital was used to obtain information on pattern and outcome of skin diseases seen from January 2010 to December 2011. The frequency of pediatric dermatoses and their distribution patterns were studied. The results revealed that out of the 9279 Patients attending Dermatology out patient department of Community Based Medical College Hospital, 1753 (18.89\%) Children were identified with involvement of skin diseases. Age range related to disease was found between one day old to 14 years. The most frequent skin condition was exposure to fungal diseases which was $25.67 \%$ followed by scabies $24.10 \%$ and eczema $20.25 \%$. Infectious skin diseases represent considerably a high percentage of skin disorders encountered in pediatric population.
\end{abstract}

Key words: Pediatric, rural, skin diseases.

CBMJ 2013 Jan: Vol 02 No 01: P: 09-14

\section{Introduction}

Dermatoses are a wide-spread health problem among children though not responsible for mortalities but for morbidities. It has been neglected both by the community and health personnel. Skin of the child is more prone to develop skin diseases. ${ }^{1} \mathrm{~A}$ number of studies have been conducted to understand the skin problems in child population which have recorded wide ranging prevalence and patterns. ${ }^{2-4}$ Various epidemiological studies have been undertaken across the world including India to study the pattern of pediatric dermatoses. ${ }^{5-18}$ The incidence of pediatric dermatological problems varies widely from country to country. Skin diseases, though very common in many developing countries, are often not regarded as a significant health problem ${ }^{19-21}$ even when serious diseases may be heralded by skin changes. Studies carried out among children have indicated that the infective disorders mainly pyoderma and scabies are major diseases identified by the primary health care facility in developing countries 20,22 .
1. * Dr.Md.Hadiuzzaman

Associate Professor of Dermatology \& VD, Community Based Medical College, Bangladesh.

2. Prof. Dr. Muhammad Hasibur Rahman Professor (CC) of Dermatology \& VD, Community Based Medical College, Bangladesh.

3. Dr. Nahida Islam

Assistant Professor of Dermatology \& VD, Community Based Medical College, Bangladesh.

4. Dr. Md.Shahidul Islam

Assistant Professor of Dermatology \& VD, Community Based Medical College, Bangladesh.

5. Dr.Sabrina Alam Mumu Assistant Professor of Dermatology \& VD, Community Based Medical College, Bangladesh

6. Mohammod Kamruj Jaman Bhuyan Associate Professor, Department of Statistics, Bangladesh Agriculture University

* Address of Correspondence:

E-mail : rokon.skin@yahoo.com Mobile : 01818070740 
The prevalence studies from the community $21,23,24$ dermatology clinics ${ }^{25-27}$ general out patient clinics ${ }^{22}$ and primary health centers ${ }^{20}$ have evidenced some variations in the types of diseases found in the different settings. Community studies revealed the high burden of dermatophytosis among school children in urban $^{23,24}$ and rural ${ }^{21}$ areas in Nigeria while dermatology clinics reported higher incidence of atopic disorders ${ }^{25-27}$. It has been perceived from data information that patients with poor social status having skin disease individually possess the general behavior to remain indifferent and avoid seeking medical care in other ${ }^{28,29}$. This behavior is dependent and interrelates with the severity the ailment to be perceived and the availability of medical assistance. As for example patients with scabies and pyoderma are more likely to seek medical attention probably due to the more severe symptoms and distress evolved and experienced with these conditions ${ }^{30}$, because these disorders cause severe discomfort. Moreover the ready accessibility of drugs across the counter in this country also lends to self medication and decreases the attendance of the patient to a health care facility. It has been further demonstrated that the ability of the attending doctor to manage the ailment depends on the skills and knowledge acquired during the undergraduate training and/or his/her exposure to specialist training. In this viewpoint the WHO (World Health Organization) in a workshop in 2004 advocated for strengthening of community dermatology for developing countries while others have called for training of health workers in the diagnosis and management of skin diseases ${ }^{31}$. These efforts would definitely be beneficial to help redressing the problem of misdiagnosis and management of skin disorders. The purpose of this investigation has therefore been directed to find out the magnitude of skin disease load and types of problems associated with disease occurrences in the rural community.

\section{Methods}

Since the inception Community Based Medical College Hospital is serving rural peoples of Mymensingh district, Bangladesh and is devoted to provide unrestricted medical care and management. The department of Dermatology in the hospital is largely involved in rendering curative services and engaged in terms of caring and management through consultancy. In this study the register records of patients attending the Community Based Medical College Hospital Dermatology out patients department was employed to collect data of children who were presented with skin problems for the time period between January 2010 and December 2011.

For the purpose of the study the skin disorders diagnosed are broadly classified into pyoderma, superficial mycoses, allergic dermatitis, benign viral tumors, non specific dermatitis and others. The term pyoderma was used for those diagnoses termed impetigo, carbuncle, furunculosis, pustular skin eruptions, septic skin lesions, and cellulitis. Viral infection includes Verruca, Herpes simplex, Herpes Zoster, Molluscum contagiosum, chicken pox. Superficial Mycoses was used to designate diagnosis that included tineasis, tinea corporis, tinea capitis, pityriasis versicolor, skin mycosis and fungal infection. Diagnoses that were termed allergic dermatitis comprised infantile eczema, allergic dermatitis, contact dermatitis, Seborreic dermatitis, irritant dermatitis and atopic dermatitis. Psoriasis, Lichen planus, Acne, Vitiligo, pemphigus, albinism, fixed drug eruption, keloids, and milia were grouped under others. Data analysis was performed using the software SPSS (Statistical Package for Social Sciences) Version 17.0. Frequency tables were used to describe the categorical variables. 


\section{$\underline{\text { Results }}$}

The demography of paediatric patients showed that two hundred sixty six (15.17\%) children were below < 01 yrs old, six hundred nine (34.74\%) children were between 1-5 years followed by four hundred fifty six (26.01\%) in between 6-10 yrs and the rest four hundred twenty two $(24.07 \%)$ children were found between 11-14 years old (Fig 1).

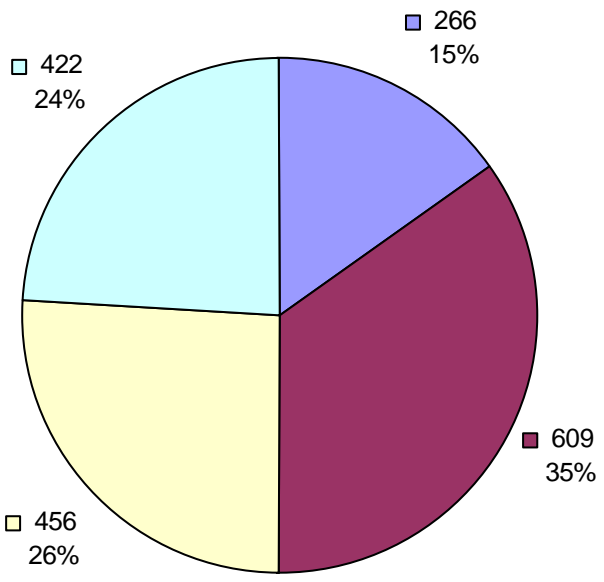

Figure-1: Distribution of Patients according to age.

During the period under study, nine thousand, two hundred and seventy nine (9279) patients attended the Dermatology department of Community Based Medical College Hospital, Mymensingh were involved with dermatoses. Out of these registered patients one thousand seven hundred fifty three (18.89\%) showed skin lesions as their primary complaint. Data presented in Table 1 represent the distribution of the disease in term of age. It is evidenced that the skin diseases were prevalent in children between one day old age to fourteen years. 
Original Article

Table 1: Pattern and frequency of Skin diseases seen among the children in Dermatology out patient department of CBMCB Hospital.

\begin{tabular}{|c|l|l|l|l|l|l|c|}
\hline $\begin{array}{c}\text { Age } \\
\text { (Years) }\end{array}$ & $\begin{array}{c}\text { Pyoderma } \\
(\%)\end{array}$ & \multicolumn{1}{|c|}{ Scabies (\%) } & $\begin{array}{c}\text { Superficial } \\
\text { Mycosis (\%) }\end{array}$ & Eczema (\%) & Viral (\%) & Others (\%) & Total (\%) \\
\hline$<01$ & $27(15.70)$ & $69(16.31)$ & $85(18.89)$ & $61(17.18)$ & $03(7.89)$ & $21(6.67)$ & $266(15.17)$ \\
\hline $1-5$ & $78(45.35)$ & $183(43.26)$ & $149(33.11)$ & $109(30.70)$ & $10(26.32)$ & $80(25.40)$ & $609(34.74)$ \\
\hline $6-10$ & $42(24.42)$ & $97(22.93)$ & $126(28.00)$ & $84(23.66)$ & $12(31.58)$ & $95(30.16)$ & $456(26.01)$ \\
\hline $11-14$ & $25(14.53)$ & $74(17.49)$ & $90(20.00)$ & $101(28.45)$ & $13(34.21)$ & $119(37.78)$ & $422(24.07)$ \\
\hline Total (\%) & $172(9.81)$ & $423(24.10)$ & $450(25.67)$ & $355(20.25)$ & $38(2.17)$ & $315(17.97)$ & $1753(100)$ \\
\hline
\end{tabular}

Pyoderma was found in 172 (9.81\%), scabies in 423 (24.10\%), dermatitis/eczema in 355 $(20.25 \%)$, superficial mycoses in $450(25.67 \%)$ and others in $315(17.97 \%)$. The other diagnoses were vitiligo, pityriasis rosea, hyperkeratosis, puritis, naevi and drug reaction, birth mark, haemangioma, psoriasis and alopecia.

The highest cutaneous disease burden was seen in those children aged 1-5 yrs followed by those 6-10 year old. Viral infection was least common among children. Majority (25.67\%) of the patients were with a diagnosis of fungal infection.

With regards to scabies it was most common among children aged 1 to 5 yrs $(n=183,43.26 \%)$ followed by children in age group 6-10 yrs ( $n=97,22.93 \%)$. It was found in several members of the same family and some of the lesions were superimposed infections. During the investigation period it was noted that there was a clustering of pyoderma during the warm wet season of April to September. The other diseases did not depict any remarkable seasonal variation.

\section{Discussion}

The health seeking behavior for skin diseases in patients of Bangladesh ambient although is low but is comparable with some industrialized countries ${ }^{29}$ where 90 out of 129 students with symptomatic skin disease did not seek medical assistance. In the Netherlands only about $1 \%$ of consultations to the General practitioners were for skin diseases ${ }^{30}$. In contrast to our self-devoted experience, workers in Mali have recorded $11.7 \%$ of consultations from eight health centers and these were destined to skin diseases and this result is in agreement with the morbidity prevalence in our environment ${ }^{32}$. The ability of the parents to purchase any drug over the counter could also contribute to the self medication that occurs resulting in late presentation by patients. It is possible that patients might also be treated by child specialist. Infective conditions were the most frequent factor that leads to seeking health care. The development of this situation assumes to be similar with the finding in the General out Patient of the University College Hospital $(\mathrm{UCH})$ Ibadan and other health facilities ${ }^{20,21}$, but differs from the impactness observed in specialist dermatology clinics ${ }^{25-}$ 27 . It is however justified to believe that the capability of other non specialist doctors to identify and treat pyoderma and scabies could be the basis of eliminating short comings directing to the non referral transfer of such cases. There was no obvious peak age for scabies but an increase in occurrences was evidenced between those aged $1-5$ years.

Superficial mycoses (SM) were evidenced in $25.67 \%$ of our patients. This prevalence is more than that of the Ibadan ${ }^{22}$ series from GOP which is estimated to be $10.4 \%$. The majority of these patients were found in 1 to 5 years old group. However this result differs from other reports which demonstrated that $\mathrm{SM}$ is more common in patients aged 13 years and above. The figures in this study were found relatively low considering the data from community studies ${ }^{22}$ and school children ${ }^{19,23,24}$. This could be thought to be a reflection of attitude in respect to the poor health seeking behavior of persons usually seen in developing countries or focus on the fact Africans consider scalp ringworm as 
normal and would not seek treatment in a health facility ${ }^{28}$.

Eczema observed in $20.25 \%$ of the children was more common in patients less than 5 years old which is similar with the study from Ibadan ${ }^{22}$.It interesting to note that the majority of the children with allergy had infantile eczema and is usually recorded at a lower age bracket.

The high prevalence of pyoderma evidenced during April to September period which is predominantly wet season in Bangladesh has also been documented by other studies and is thought to be due to the increased humidity in these months. We did not find an obvious increase in allergic dermatitis during the dry months of October to March.

\section{Conclusion:}

From this study it is demonstrated that the frequency distribution of skin diseases found among children less than 14 years old is infective in origin with fungal causes being the maximum. In order to reduce dermatoses in rural children of Bangladesh, it is important to control at least pyoderma, fungal infections and severe forms of malnutrition. Improvement in personal hygiene, sanitation, building awareness regarding dermatoses, timely medical advice and provision of commonly required drugs at the grass-root level are necessary to reduce the prevalence of dermatoses in children. 


\section{References}

1. Fitzpatrick TB, Arndt, Clario, et al, Dermatology in general medicine. New York : Blackwell, 1971.

2. Sharma N K, Garg N. Pattern of skin diseases in urban school children. Ind $J$ Dermatol Venereol Leprol 1986;6:330-1.

3. Patel $R B$, et al. Paediatric dermatoses and eradication in slums. Ind Paed 1982;49:135-9.

4. Koley SK, Sen MK, Sengupta SN. Incidence of skin diseases in children in the distric of Bankura Ind J Paed 1975;42:104-9.

5. Figuerosa JI, Fuller LC, Abraha A, Hay RJ. The prevalence of skin disease among school children in rural Ethiopia - a preliminary assessment of dermatologic needs. Pediatr Dermatol 1996;13:378-81.

6. Nanda A, Hasawi FA, Alsaleh QA. A prospective survey of pediatric dermatology clinic patients in Kuwait: An analysis of 10,000 cases. Pediatr Dermatol 1999;16:6-11.

7. Wenk $\mathrm{C}$, Itin $\mathrm{PH}$. Epidemiology of pediatric dermatology and allergology in the region of Aragau, Switzerland. Pediatr Dermatol 2003;20:482-487.

8. Hon KL, Leung TF, Wong $Y$, Ma KC, Fok TF. Skin diseases in Chinese children at a Pediatric dermatology centre. Pediatr Dermatol 2004;21:109-22.

9. Gul U, Gonul M, Kilic A, Bilgili S. Pediatric skin disorders encountered in a dermatology outpatient clinic in Turkey. Pediatr Dermatol 2008; 25: 277-278.

10. Rao SG, Kumar P, Kuruvilla M. Prevalence of various dermatoses in school children. In $\mathrm{J}$ Dermatol Venereol Leprol 1999;65:126-7.

11. Dogra S, Kumar B. Epidemiology of skin diseases in school children: A study from Northern India. Pediatr Dermatol 2003;20:4703. Back to cited text no.

12. Sharma NL, Sharma RC. Prevalence of dermatologic diseases in school children of a high altitude tribal area of Himachal Pradesh. In J Dermatol Venereol Leprol 1990;56:375-6.

13. Bhatia V. Extent and pattern of paediatric dermatoses in rural areas of Central India. In J Dermatol Venereol Leprol 1997;63:22-5.

14. Ghosh SK, Saha DK, Roy AK. A clinicoaetiological study of dermatoses in paediatric age group. In J Dermatol 1995;40:29-31.

15. Negi KS, Kandpal SD, Parsad D. Pattern of skin diseases in children in Garhwal region of Uttar Pradesh. In Pediatrics 2001;38:77-80.

16. Karthikeyan $K$, Thappa DM, Jeevankumar $B$. Pattern of pediatric dermatoses in a referral centre in South India. In Pediatrics 2004;41:373-7.

17. Sardana K, Mahajan S, Sarkar R, Mendiratta $V$, Bhushan P, Konanne RV, et al. The spectrum of skin disease among Indian children. Pediatr Dermatol 2009;26:6-13.

18. Morris A, Rogers $M$, Fischer $G$, Arch $B$, Williams $K$. Childhood psoriasis: A clinical review of 1262 cases. Pediatr Dermatol 2001;18:188-98.

19. Ajao AO, Akintunde C. Studies on the prevalence of tinea capitis in Ile-IfeNigeria. Mycopathol. 1985; 98:43-48.

20. Odueko DM, Onayeni $O$, Oyedeji U. a prevalence survey of skin diseases in Nigerian children. Nig J of Med. 2001;10:64-67.

21. Ngwogu A, Otokunefo TV. Epidemiology of dermatophytoses in a rural community in Eastern Nigeria and review of literature from Africa. Mycopathologica. 2007;164:149-158.

22. Alabi GO. The pattern of common childhood dermatoses in Ibadan. Nig J Paed. 1980;7:3942. PubMed.

23. Ogunbiyi AO, Owaje E, Ndahi A. Prevalence of skin diseases in school children in Ibadan, Nigeria. Ped Derm. 2005; 22:6-10.

24. Oyedeji OA, Onayemi O, Oyedeji GA, Oyelami $O$, Aladekomo TA, Owa JA. Prevalence and pattern of skin infections and infestations among primary school pupils in ljesha Land. Nig J Paed. 2006;33:13-17.

25. Ogunbiyi AO, Daramola OOM, Alese OO. Prevalence of skin disease in Ibadan Nigeria. Int J Derm. 2004;43:31-26.

26. Yahya $H$. Change in pattern of skin disease in Kaduna, North-central Nigeria. Int J Derm. 2007;46:936-943.

27. Nnoruka EN. Skin disease in south-east Nigeria: current perspectives. Int J Derm. 2005;44:29-33.

28. Bagaya GM, Odhiambo MO, Oniang'o RK. Mother's health seekingbehaviour during child illness in a rural Western Kenya Community. Afr Health Sci. 2005;5:322-327.

29. Fung WK, Lo KK. Prevalence of skin diseases among school children in a school health center in Hong Kong. Ped Derm. 2000;17:440446.

30. Mohamanedamin RSA, van der Wouden JC, Koning S, van der Linden MW, Schelleris FG, van Suijlekom-Suit LWA, Koes BW. Increasing incidence of skin disorders in children? Comparison between 1987 and 2001. BMC Derm. 2006; 6:4-11.

31. Mahe A, N'Diaye HT, Bobin P. The proportion of medical consultations motivated by skin diseases in the health centers of Bamako (Republic of Mali) Int J Dermatol. 1997; 36:185-186.

32. Onayeni O, Isezuo SA, Njoku CH. Prevalence of different skin conditions in an out patient setting in north western Nigeria. Int $\mathrm{J}$ Dem. 2005; 44:7-11. 